\title{
Aggregate-then-Curate: how digital learning champions help communities nurture online content
}

\author{
Andrew Whitworth ${ }^{\mathrm{a} *}$, Fred Garnett ${ }^{\mathrm{b}}$ and Diana Pearson ${ }^{\mathrm{a}}$ \\ ${ }^{a}$ School of Education, University of Manchester, Manchester, UK; ${ }^{b}$ London Knowledge Lab, \\ Institute of Education, London
}

(Received 3 May 2012; final version received 27 September 2012)

Informational resources are essential for communities, rooting them in their own history, helping them learn and solve problems, giving them a voice in decisionmaking and so on. For digital inclusion - and inclusion in the informational and democratic processes of society more generally - it is essential that communities retain the skills, awareness and motivation to create and manage their own informational resources.

This article explores a model for the creation of online content that incorporates the different ways in which the quality and relevance of information can be assured. This model, "Aggregate-then-Curate" (A/C), was developed from earlier work concerning digital inclusion in UK online centres, models of informal e-learning and ecologies of resources. $\mathrm{A} / \mathrm{C}$ shows how creating online content can be viewed as a 7-step process, initiated by individuals but bringing in "digital learning champions", other community members and formal educational institutions at different stages. A/C can be used to design training to help build the capacity to manage community informational resources in an inclusive way. The article then discusses and evaluates MOSI-ALONG, a Joint Information Systems Committee (JISC) funded project founded on these ideas, which illustrates how $\mathrm{A} / \mathrm{C}$ can be used to design training to help build the capacity to manage community informational resources in an inclusive way. This conclusion is supported by evaluations of the work done so far in MOSI-ALONG.

Keywords: curation; digital inclusion; object-centred sociality; ecology of resources; inclusion; online content; social media; digital learning champions; communities

\section{Introduction}

This article presents and then tests an original model for the process of developing collections of online content in a digitally inclusive way. This model, Aggregate-thenCurate (hereafter, A/C), was developed for and then tested through the MOSIALONG project which ran in Manchester, UK, during 2011. MOSI-ALONG brought together a variety of organisations in the city (named in the acknowledgements) and members of local communities. Through this interaction were developed "digital learning champions" (DLCs). DLCs are individuals who could help both their own and other communities to nurture and manage collections of online content. Thus, DLCs catalyse the A/C process.

*Corresponding author. Email: drew.whitworth@manchester.ac.uk

RLT 2012. (C) 2012 A. Whitworth et al. Research in Learning Technology is the journal of the Association for Learning Technology (ALT), a UK-based professional and scholarly society and membership organisation. ALT is registered charity number 1063519. http://www.alt.ac.uk/. This is an Open Access article distributed under the terms of the Creative Commons "Attribution 3.0 Unported (CC BY 3.0)" license (http://creativecommons.org/licenses/by/3.0/) permitting use, reuse, distribution and transmission, and reproduction in any medium, provided the original work is properly cited. 


\section{A. Whitworth et al.}

$\mathrm{A} / \mathrm{C}$ is a model of change that can describe how the skills necessary for digital inclusion can be conceived within a single theoretical framework and then developed in individuals and communities as a whole. It is a significant tool for analysing any initiative or programme that claims to be developing digital literacy or content production skills in learners.

\section{Background: stewarding and community informatics}

Individuals and the different communities into which they gather share resources (Clarke 1996, p. 24). These resources mediate their activity within the world and include people, technologies, skills, memories, symbols and the facilities for learning. All of which exist in dynamic interrelationships, or as Luckin has called them, ecologies of resources (Luckin 2010). The metaphor is carefully chosen. Ecologies are not static but evolve, and any ecology needs to be sustainable, well managed, accessible, diverse, and healthy or of good quality (Whitworth 2009, p. 21).

Communities that share learning needs are termed by Wenger as "communities of practice" (Wenger 1998). The ecologies of resources created by communities of practice, in the digital era, have been called "digital habitats" by Wenger, White and Smith (2009). These authors explore how communities create and then steward digital habitats to help them meet their learning needs. Stewarding - active work oriented towards sustaining a community's digital habitat - is a "creative practice" and a "critical part of community leadership, facilitating a community's emergence or growth" (ibid, p. 25).

However, the skills and capacity required for stewarding are rarely distributed throughout the community as a whole. Instead, they tend to be invested in individuals who "take responsibility for a community's technological resources for a time" (Wenger, White, and Smith 2009, p. 24). Because a community with a limited number of stewards, perhaps only one individual, would suffer if the steward(s) left the community for some reason, it is best if stewards also seek to build the capacity for stewarding in others and thereby distribute the capacity to sustain the community's digital habitat.

Stewarding may originate from outside the community, and it is partly the historic role of formal and non-formal educational institutions to assist with the maintenance and preservation of a community's informational resources. However, such institutions, which include universities, museums, libraries and training providers, have historically presented and organised their resources in ways that do not necessarily make them accessible to members of the communities on whose behalf they may claim to be acting. For example, different terminologies may be used to present or organise the resources from those that are meaningful for community members (see Simon 2010). Barr (2005), in her counter-critique of those who oppose "widening participation" in the museum sector, also addresses these ideas. She points out how the sector typically organises itself around exclusion, not inclusion, and is criticised for "dumbing down" if it does attempt to reach out to a substantial number of potential visitors who, though they support the sector through tax payments, never feel motivated to visit.

Generally, it is the role of stewards to contextualise and make meaningful the resources on which the community can potentially draw. Thus, it is necessary to develop methods, applicable in practice, which can assess and promote inclusive stewarding. Such methods maintain the essential connection between the members of 
the community and the resources that they need to learn and thus act effectively in the world. This involves taking an active and inclusive role in maintaining the informational and technological resources on which they depend.

Stewarding is a dynamic process, as recognised by Wenger, White and Smith (2009). It involves not just technical activities, but learning: raising the awareness of community members, distributing skills, making connections, and thus creating new resources, rather than just consuming existing ones. It involves the development of an "architecture of participation" (Garnett and Ecclesfield 2008) within which community members are included, and through which they can develop professionalised skills through engaging in activities and reflecting on the experience. Participation becomes, in itself, a learning process; active involvement in the maintenance of a digital habitat is akin to other forms of social activism, all of which stimulate learning (Blaug 2007). To accurately reflect upon the importance of learning in our ideas, we use the term $D L C$ to describe stewards.

Stewarding is a manifestation of what Gurstein describes as community informatics (CI). CI is based on the assumption that communities (Gurstein 2007, p. 11) "have characteristics, requirements, and opportunities that require different strategies for information and communication technology (ICT) intervention and development from the widely accepted, implied models of individual or in-home computer/Internet access and use.” CI (Gurstein 2007, p. 34):

favors 'effective use' rather than 'passive access'; production rather than consumption; and information or knowledge creation and use, as the basic model for end-user computing by those at the system periphery. Thus, rather than a concern with responding to, for example, the 'Digital Divide' by extending opportunities for technology or internet access, the issue is redefined as finding ways of using ICTs to respond to issues and requirements that are meaningful and significant in the daily lives of individual users within their communities.

Therefore, CI recognises that by simply having access to the technology is not "digital inclusion". Truly inclusive ICT is empowering, helping the community produce information, and raising awareness about the possibilities for action inherent in the technology. An inclusive system can be shaped by communities, and the DLCs that emerge from within them or act on their behalf. This supports Seale's conclusion (2010, p. 3) that while "access" [to ICT] is certainly part of digital inclusion, a full definition of the idea must also encompass use [of ICT]; empowerment [through ICT]; and participation [in ICT].

\section{Origins}

\section{Formal, informal and non-formal learning}

In 2002, Fred Garnett (one of the authors of this article), was asked to develop a Digital Divide Content Strategy by the UK Department for Education and Skills and was commissioned to carry out some research into how people learnt in UK online centres as part of the Metadata for Community Content project. This produced a research report by Smith and Cook (2002), which established the lifecycles model of UK online centres development. This model was evolved into a model of informal e-learning (Cook et al. 2002) to help guide learning design in UK online centres. 


\section{A. Whitworth et al.}

The research conclusion was that there is no digital content that, in itself, alleviates digital divides. Rather, a more complicated picture exists concerning content creation and the learning relationships that support such a process. The recommendation of the research was that content creation tools and new skills in the "trusted intermediaries" who support learning in digital contexts were needed, designed for social inclusion, by allowing learners to follow those interests that motivated them. This was called the Community Development Model of Learning (Garnett 2005). Some of these ideas were incorporated into the NLN aclearn.net project (2003-2007), which provided tools for content creation (such as web quests), a hosting platform and training in their use (NIACE e-guides). Critically, it was a learner-centric model that enabled digital inclusion by designing for learner interests.

Few models of learning are genuinely learner-centric. Ecologies of resources are always filtered in some way. Choices will be made about what resources are available or acceptable. Direct restrictions can be placed on how community members can access or use resources (e.g. needing to register to gain access to a website; legal restrictions such as copyright). If community learning is accredited, learners' attention will be directed towards certain resources and away from others by resources such as syllabi and assessment criteria. More indirectly, filtering may take place by restricting awareness, depriving users of skills training, or allowing access to certain technologies but not others. Therefore, filtering can take place before a user gets the opportunity to directly exercise their own judgment about the relevance and quality of available resources. Therefore, digital inclusion is partly a matter of how much of the filtering process is done by the user and how much on their behalf.

In 2009, in order to re-interpret the EU's planned integration of informal, nonformal and formal learning following the implementation of the Bologna Process, Ecclesfield and Garnett produced the 'Proposed model of the relationships between informal, non-formal and formal learning' (Garnett and Ecclesfield 2009) - since renamed the Emergent Learning Model - a more dynamic model of self-organised learning than the Ecology of Resources. This model considered how resources are filtered in different ways depending on whether the learning is taking place in formal, non-formal or informal settings. Education is largely considered formal, a notion that shapes resources from the top down. Formalised education flows start with an institution that offers accreditation and then provides resources and groupings that meet that expressed goal. On the other hand, learning starts with individuals and communities. The desire to learn, a natural desire, is often constructed as informal learning and comes from individuals or groups with interests who may organise and access resources in pursuit of that interest:

In the real world, when people need to learn something, they usually do not remove themselves from their normal situations and force themselves into sterile rooms to listen to lectures on formal principles about what they are doing. Rather, they tend to form work groups (practice communities), assign roles, teach and support each other, and develop identities that are defined by the roles they play in support of the group. (Jonassen et al. 2003, p. 71)

Garnett and Whitworth also produced an interpretation of the model in an unpublished paper called "Towards the Learner-generated Library" which examined how user-generated content, produced in various contexts across a city, could become part of a digital library, or repository. This article reflected the idea of Simon (2010) of object-centred sociality - the notion that community identity was, at least in part, 
sustained by the collections of artefacts or content that helped form part of the community's informational resources - and became the foundation of the Joint Information Systems Committee (JISC) funded MOSI-ALONG project. This ran in 2011 and was initiated to test parts of the learning model.

\section{Working together to sustain good-quality ecologies of resources}

The formal, non-formal and informal sectors can offer mutual support to one another. It would be erroneous to state that all filtering - the organisation of resources - should be done by learners and/or communities based on their own subjective needs. Whitworth's tripartite model (2009, pp. 11-17; in press) shows how the sphere of resources is filtered in three ways:

- At the objective level, through the application of generic rules, principally, scientific method: thus, choices made as the result of the research process.

- At the subjective level, based on individual preferences: these may be consistent and conscious, but can also be sub-conscious and possibly irrational.

- At the intersubjective level, in which decisions are agreed upon within groups: these may be open and inclusive, but also closed, distorted by power relations or become deeply embedded into conventions that go unscrutinised.

Thompson (2008) and Keen (2007) both forcefully criticise the tendency in the Web 2.0 era to use only subjective and intersubjective criteria to judge the quality of online resources. Keen criticises the Web 2.0 era as one in which society's informational resources are being degraded through what he calls "the cult of the amateur". Traditional locations of "gatekeeping", such as editing, academic peer review, publishing expertise and curatorial authority (of the sort exercised by museums and other guardians of resource collections) are being bypassed and Keen sees this having deleterious effects on the sphere of online information.

Shenk (1997) also noted that if communities looked only to their own, selfgenerated criteria for judging the relevance of resources, they would be less able to share information across their boundaries (or create what Wenger (2000) terms boundary objects). Their ability to process new information, synthesise it and thus learn from the insights of other communities would be damaged as the informational sphere fragments into "micro-communities" (Shenk 1997, p. 127: see also Habermas 1987, p. 355). It is through these kinds of boundary interactions that communities receive fresh informational inputs.

Thus, an exchange of value between informal, learner-driven processes and more formal educational environments is desirable. DLCs, at least in part, orchestrate these different inputs. Community members judge the quality of their learning processes and their use of technology, based on relevance, need, informal collaborative learning processes, individual skills and capacities. External partners can support community learning by also acting as DLCs, but in different ways, providing training, advice, content (pre-existing, or new), technologies and, ultimately, accreditation as the different developmental phases within the community support each other (Rosson and Carroll 2009). A range of value judgments which incorporate subjective or personal values - intersubjective, or community values; and objective, or generic values (Whitworth 2009, pp. 11-17) - all come together to sustain the quality of the digital habitat and the activities that can develop therein. 


\section{A. Whitworth et al.}

Giaccardi (2012, p. 2) has observed that "mobile and ubiquitous technologies are accelerating these changes by enabling users to participate, spontaneously and continuously [emphasis added], in activities of collection, preservation and interpretation of digitized heritage content and new digitally mediated forms of heritage practice." The boundaries between the different realms - amateur and professional, individual and institutional - are not erased, but potentially become more permeable. There is the possible emergence of a more inclusive, participatory culture, "characterized by relatively low barriers to public artistic expression and civic engagement, strong support for creating and sharing one's creations with others, and frameworks for formal and informal mentorship to novices" (ibid, p. 3). This is our basic view of digital inclusion, as applied to the creation of online content that is relevant to communities.

\section{The A/C model ${ }^{1}$}

A/C essentially models the creation of community-defined, object-centred and goodquality collections of informational resources. It directly responds to the criticisms of Keen and Thompson: while "amateurism" and a lack of quality in the production of online resources is certainly possible, it is not in any way inevitable. A/C is a process by which the quality of online resources can be assured, having been validated from the perspective of each domain of value: objective, subjective and intersubjective. Ideally, the process has seven stages, each of which validates the quality of those that precede it.

\begin{tabular}{|c|c|c|c|}
\hline No. & Stage & Involved parties & Measures of quality or value \\
\hline 1 & Identification & Participant & Individual, subjective \\
\hline 2 & Initial aggregation & $\begin{array}{l}\text { Participant, community learning } \\
\text { champion }\end{array}$ & $\begin{array}{l}\text { Community-led, } \\
\text { intersubjective }\end{array}$ \\
\hline 3 & Digital creation & Participant, DLC & Technical, objective \\
\hline 4 & Digital aggregation & Participant, DLC & $\begin{array}{l}\text { Community-led, } \\
\text { intersubjective }\end{array}$ \\
\hline 5 & $\begin{array}{l}\text { Sequencing and } \\
\text { curation }\end{array}$ & Participant, DLC & Curatorial, objective \\
\hline 6 & $\begin{array}{l}\text { Social media } \\
\text { aggregation }\end{array}$ & Social media, DLC & $\begin{array}{l}\text { Community-led, } \\
\text { intersubjective }\end{array}$ \\
\hline 7 & Accreditation & Many possible organisations & Formal, objective \\
\hline
\end{tabular}

(1) Identification: The initial motivation for creating resources must come from the community participant (an individual, or a group), even if the motivation is in response to an external stimulus, e.g. a request to participate in a project. There will be at least one existing resource that the participant has in mind. This may be a physical object, a text (digital or otherwise), or tacit knowledge such as a skill, personal narrative, etc. The resource belongs to the participant and not to the project or to the partner institutions.

(2) Initial aggregation: This stage begins the process of connecting together resources by revealing links between them, suggesting appropriate groupings, potential learning pathways and so on. This is a social process and so must involve other members of the community, but not necessarily involve digital media. Often, it will take place very informally, as community members validate one another's 
opinions about what information is useful, sometimes explicitly but often with reference to implicitly held, shared views - the sort of thing that binds people together in "communities" in the first place. However, it may also involve more organised and/or formal processes. What this stage entails is the intersubjective validation of initial, subjective ideas by members of the community.

(3) Digital creation: Once resources and connections between them have been identified by the community, some form of digital representation can be created. Even where some existing resources, first identified then aggregated in Stages 1-2, are already in digital form, the connections between them may need expressing as digital content in their own right.

A DLC would help here if they were at a different "developmental phase" in their work with, and experience of ICT, and could thereby provide technical assistance to the creation of digital artefacts. A particular resource might be very relevant and timely. However, its usefulness will be diminished if it is, for example, an inaudible recording. Is metadata in place, can the resource therefore be found by others? Is the appropriate format, or medium, being exploited? Is the material legal? These are more objective filtering criteria than apply at earlier stages.

(4) Digital aggregation: At this stage, resources are informally aggregated in a community-driven way. Digital aggregation involves using social links that either already exist (and may, or may not, have played a role in the initial aggregation at Stage 2), or which are discovered at the digital creation stage. Once again, this process may be supported by a DLC.

(5) Sequencing and curation: Sequencing is when the aggregation process takes on a more structured form. The collection of resources begins to demonstrate its potential to solve problems or drive learning outcomes both within and outside the community. Learning pathways or other broader narratives begin to be addressed through the aggregation process in a coherent way.

This is the stage at which curation comes into play. The subjective and intersubjective values assigned to the community informational resources by individuals and other community members, are validated here by interests that are partly external. This is a significant moment for the collection. If "curator" is broadly defined as "a person in charge of something ... a guardian" (from Chambers English Dictionary), curation can therefore be defined as the management of a collection of resources at a fundamental level. As Simon (2010) recognises, and as our background discussion concluded, it is the level of participation in curation that is significant. Sequencing is the stage at which the resources' quality begins to be judged by institutions that may still be familiar with the general context from which they emerged, but which are essentially external to the community. The role of a DLC here would be to facilitate the interaction across the boundary for mutual benefit, helping the community members reflect on, and thereby learn from, the interaction: but also helping the institution learn from the community.

(6) Social media aggregation: Their quality validated by a wide range of interests that remain local, resources that reach a certain standard - judged either by technical quality, informational quality, or widespread relevance and appeal - are then widely disseminated. The resources "go viral" in some form or another. The community that is now validating them and assigning them value is now much wider in scope and may exist in contexts that are quite distinct from that in which the resources initially emerged. 


\section{A. Whitworth et al.}

The effective use of a social media aggregator, such as a blog or a wiki or a more dedicated social media aggregator offered by a provider, would represent a shift in the participants' mastery of a range of social media. This would indicate that they have a range of effective digital skills to use to curate digital content, as well as to negotiate with a number of third parties including groups, such as local history groups, as well as cultural and educational institutions.

(7) Accreditation: Collections of resources may be recognised as definitive, publishable, in need of protection, or other such formal recognition of their value (quality, distinctiveness, relevance). Individuals and communities may have their work on the resources recognised by the formal award of credit from an educational provider, or some other mark of status or achievement, perhaps an exhibition, further commissions, etc.

It must be stressed that this model is an ideal. In reality, later stages are often never reached, and some may be bypassed, or take place without the participation of effective learning champions, adequate levels of community participation, and so on. This is, however, the model that drove our design of the MOSI-ALONG project, and it was through engaging with this project that we were able to refine elements of the model and investigate what happens if stages are skipped or never reached.

\section{Project methodology: the theory of change}

Digital inclusion cannot arise through outside influence. As Kemmis says (2001, p. 91, referring to Habermas 1974), "others cannot do the enlightening for participants; in the end, they are or are not enlightened in their own terms". Instead, true inclusion must be community-driven.

CI is not an objective ideal to be achieved, a set of criteria which can be applied in a generic way to the "measurement" of inclusion. Such an approach is reifying a technical notion of "access" and would result in the limited, but prevalent, view of the issue of digital inclusion. Instead, CI is practice and outcome driven, not methods or theory driven (Gurstein 2007, p. 31). A CI approach "is one which ideally begins with the local community identifying a need or a possible application and then beginning a process of working with those with the requisite skills to respond or to satisfy that need, always within a context where the local community is in control and is directing the process of its own technology enablement" (ibid, p. 61).

Therefore, we present the MOSI-ALONG project as a case study of work oriented towards digital inclusion. The objective of the JISC programme, which funded it, was to facilitate the production and validation of community content (http://www.jisc. ac.uk/whatwedo/programmes/digitisation/econtent11.aspx - last accessed September 25 2012), and we did so by bringing together formal, informal and non-formal learning institutions in the Manchester area and structuring the interactions along the lines of the A/C model. We did this by identifying individuals and communities who had an interest in producing digital content, and then facilitated the process through giving them access to DLCs and using these links to help develop their own stewarding capacity.

Our interest was in the role DLCs played in facilitating the production of community-oriented digital content collections, but the actual content produced, and the particular skills/technologies community members needed to do so, were userdefined, and not prescribed in advance. We therefore tell the story of MOSI-ALONG not through an evaluation that assesses how well its "recipients" met pre-defined 
goals, but through presenting narratives from the project, to illustrate how we developed it around professed goals of community users.

This approach is based on the "theory of change" (ToC) approach used in the project described by Cummings et al. (2006), see also Connell and Kubisch (1998). The shortcomings of a "classical evaluation", had it been applied to MOSI-ALONG, is that the model is not adequate in identifying subtle changes and outcomes. It can adequately measure simple before-and-after measures, or participant/non-participant comparisons - but this implies that all participants begin and end at the same point. However, each of the DLCs brought very different knowledge and experience of their working and non-working environment, their computer competency and their community networks. Therefore. their start and end points, along with their own personally articulated and expected outcomes, were many and varied. A "classical evaluation" would have therefore told us very little about the impact of the project, because expected outcomes, in relation to DLCs, would be difficult to measure and may take months/years to appear.

The ToC evaluation process captures subtler outcomes, whilst taking into account the complexity of the situation. In this instance, these were the different circumstances and contexts from which the various DLCs emerged. In more detail, each DLC has:

- identified a different set of outcomes for themselves (and determined their own preferred timetable to achieve them);

- engaged in the digital learning process differently (part-time/full-time; formally, informally);

- engaged with a different community (virtual and/or real); and

- engaged in different activities to achieve their goals.

The different communities that each DLC is involved with, or trying to reach, are also different. Expectations, levels of involvement, and motivations will vary in similar ways. We summarise some of these variables in the following section.

The ToC process starts with a formal account of what, and how, activities are undertaken, and how these are expected to produce a series of changes. The focus is on short to medium term impacts on individual communities, not on longer term outcomes that may be difficult to measure - although the changes taking place may go on to produce such outcomes. One of the strengths of the ToC evaluation is its emphasis on collaboration between evaluators and practitioners. Constant feedback and the triangulation of data help to confirm or disconfirm the ToC, making the evaluation more robust. Evaluators (the project team) and practitioners (DLCs) discussed possible impacts and how they might be observed and measured, over a series of training sessions and concurrent evaluative surveys (using both questionnaires and group interviews) that took place through the course of the project. Evidence was thereby gathered that showed how far the change and impacts anticipated by the practitioners (DLCs) were actually materialising. If they did, the ToC is supported; if not, the barriers to the anticipated changes need to be identified and the ToC needs to be revised.

The evaluation of MOSI-ALONG gathered data initially through questionnaires that were used to establish the situation of each DLC: firstly, their needs, and secondly, the resources available to their community. After each round of training sessions, we used further questionnaires and interviews to review the changes that 


\section{A. Whitworth et al.}

had emerged in the DLCs' practice and the actions they were taking to transform their current situation into a more desired situation. Finally, we conducted a series of concluding interviews three months after the final training session to review the impact of these activities.

\section{Case studies}

We focus in this section on a range of different activities, which were undertaken under the MOSI-ALONG umbrella. Each of them, in different ways, sheds light on the applicability of the A/C model. In each case, we analyse how the seven stages of the model were or were not manifested, and how DLCs contributed to the quality of the content produced.

\section{The Cabinets of Curiosities}

Many early museums emerged as collections of artefacts that began as personal "Cabinets of Curiosities", and were curated by the owners of the objects before professional curators eventually took over. Simon identifies that "physical objects played a unique role in validating diverse cultural experiences" (Simon 2010, ch. 4). One of the strands in MOSI-ALONG therefore engaged learners, otherwise lacking digital skills, in the identification of objects that participants owned but which had historical relevance to Manchester and the communities, companies and institutions which made up the city's social and economic fabric. Our partner, MOSI (the Museum of Science and Industry), had particular expertise in computing, textiles, engineering and the industrial infrastructure of Manchester (e.g. canals), and these were the themes around which Cabinets of Curiosities were put together and transformed into digital content. Participants were thus curating their own Cabinets of Curiosities to tell their own stories, but with the help of DLCs located among the various project partners.

One group in particular, the Salford History Group, engaged with the project in some depth. A number of their members made films and submitted them in a competition, judging for which took place in September 2011. Some of the digital content produced can be found by searching for the \#mosialong hashtag on YouTube.

Each stage of the A/C process can be seen in this case (see below for a summary of all four cases). Individuals identified resources and through informal discussions with others (e.g. fellow members of the History Group), made selections that were then brought forward to the digital creation and aggregation stages. Sequencing and curation was achieved with the help of advisors from organisations such as MOSI who could bring a more objective perspective to bear on the artefacts, but without effacing the personal meanings the objects had for individuals. Social media aggregation was not achieved in a substantial way but occurred at some level (as shown by views of the published content), and accreditation was reflected by the competition.

It must be observed that this was a managed process. The Cabinets of Curiosities strand of MOSI-ALONG was expressly designed to lead participants through the different stages and observe the results. It is more interesting to review how the A/C model developed in more spontaneous ways, and this we do with the remaining three case studies. However, we did learn from our observations of the Cabinets. Sequencing and curation was intended to be a two-way process, with the formal and non-formal 
institutions adapting their curatorial strategies in the light of the inputs from the community, as well as the other way around. However, this never in fact took place. No new digital content was created on the MOSI site and none of the community members' stories or interpretations found their way into the museum's own collections (digital or real). Our evaluations concluded that this was because the participation of the museum in the project was driven more by its public engagement officer than its curators. This may explain why Stages 6 and 7 of the A/C model were here reached only in a limited way, though further research and evaluation will be necessary in order to fully support that conclusion.

\section{History of Manchester in 100 objects}

The "Cabinets of Curiosities" was a task assigned and managed by the project team, even if the individuals and communities who addressed it did so in a variety of different ways appropriate to their context. However, this next case study shows how an individual identified (Stage 1) their own approach to digital content, and introduced it into the MOSI-ALONG project on their own account.

During the civil unrest which hit Manchester in August 2011, a supporter of the MOSI-ALONG project, David Roberts, created an online document (using Google Docs; Stage 3) entitled "A History of Manchester in 100 Objects", and invited people via Twitter to submit references as to what made them proud to be from Manchester. Over 140 people submitted references and comments to the document. The intention was to help produce a sense of community amongst those taking part at a confusing time. (This observation was drawn from a speech given by David at the September 2011 project event, at which the competition prizes, mentioned above, were also awarded.)

The document can be viewed at http://davidcroberts.co.uk/2011/08/22/a-historyof-mancherster-in-100-objects/ [sic] (last viewed September 25 2012). The objects include archaeological finds, historic buildings, buildings of more contemporary relevance, statues and so on, but also many everyday objects, including foodstuffs, posters and the single pillar box that survived the 1996 IRA bomb in the city. Some of the comments made in the collaborative document are enlightening: contributors offer new information (e.g. on \$46), curating one another's suggestions and identify where there has been duplication. One contributor writes on $\$ 100$ (an entry that is a good summation of the collaborative development of the document): "I wonder if that is actually the point of an object based history, i.e. something completely everyday and 'normal' still be significant." The pillar box mentioned above appears on the document three times, which as one contributor recognises, shows that this everyday object has a great deal of relevance for residents of the city who remember the bombing.

This is "digital content" only in the most limited way, but it could easily form the basis of a more substantial collection of content. The fact that it has not been done yet may be significant. Although Stage 5, sequencing and curation, was reached in a limited way, this stage did not involve the participation of formal - and funded DLCs who might have been able to push the idea further and support, for example, the development of a photographic archive based around the "100 objects" (actually 169, as of September 2012). The later stages have not been reached at all. Therefore, though this is a fascinating outline for a content collection, it remains just a potentiality. An effective DLC is needed to push it through Stage 5 and into a place 


\section{A. Whitworth et al.}

where it might become a more substantial project, but such stewarding has not yet been secured.

\section{Dee and the Whalley Range site}

Dee (a pseudonym) is a community worker in Whalley Range, a suburban district of Manchester. Amongst other activities, she runs adult education classes in various subjects for women, particularly from the Asian community, who have few opportunities to associate with anyone from outside the home and family, and has been asked to set up basic ICT classes for the same group. In 2007, she won a small amount of funding to set up a website for the community (see www.whalleyrange.org), a space on which local residents and groups could create profiles of their interest, post photos and videos, promote events and raise awareness of local issues. She came to MOSI-ALONG's DLC training sessions with a stated desire to "pass my skills onto others, to share information and resources and support people to contribute, and have a say in what happens locally". Her initial hope for the training was that it would help her improve the usability of the site. She identified the principal barrier to fulfilling these objectives as being the site's dependence on her, in that she looked after it alone, with no funding to maintain or improve it, along with her other responsibilities.

After the first training session, Dee became interested in adding a Twitter feed to the site. This became her main "output" of MOSI-ALONG, and the most significant change emerging from her interactions with the other participants in the project. She saw the use of Twitter as a way of relieving some of the burden of stewarding.

Dee's work on the Whalley Range community website is a good illustration of the sort of community content which the A/C model helps understand. Starting with her initial motivation to create the site (Identification) and informal validation of this plan by other members of the community (Initial aggregation), the site came into being thanks to a grant from CN4L in 2007 (digital creation). Following MOSIALONG's DLC training sessions, Dee was motivated to add the Twitter feed, which as she says, has saved her time and distributed the adding of up-to-date news events to the site, a task which was previously problematic. This is therefore a form of digital aggregation, as through the Twitter feed the Whalley Range website is now acting as an aggregator at the community level, rather than being Dee's work alone - hash tags have allowed anyone to "push" their own information at the site.

As another example, people who have been involved in the community's Youth Opportunity programme over the last 30 years have been encouraged to use the Twitter feed, and the website generally, to share their memories about the project and help bring in the current generation of young people into the community and its resources. A project in Moss Side had involved residents using cameras to film people saying what they thought about a project ("Transition Moss Side") and that has also been re-tweeted by Dee and a link included in other communications.

As she said in her concluding interview, conducted three months after the final training sessions:

The Twitter feed has saved me time and also broadened what I can share with the community because i've found out more about what's happening locally, I don't have to put as much time into it. Before I was, like, going on everybody's site, visiting them all, copying and pasting, now I can just re-tweet. Anything that's relevant I can put a few lines in the bulletin I would send out anyway - it means there's more local stuff in there as well. 
Stages 1-4 of the A-then-C model are clearly visible in Dee's work. Prior to the training sessions, she was doing it through her own personal efforts, but the introduction of a Twitter feed allowed her to disperse the process of aggregation and thereby enhance it. Arguably, it was this innovation which allowed her to break free of the main restriction (her workload) and boost the content creation processes into the later stages. As a result, Stages 5-7 are beginning to develop also. The City Council use the Whalley Range website as a source of validated information about the community. Dee has been invited (because of the Twitter feed) to talk about the site on local radio, and through distributing information about specific projects through the website, it is gaining value as a more structured learning resource for people inside and outside the community (sequencing and curation; social media aggregation). Twitter has helped her distribute the stewarding capacity, with benefits both for Dee's satisfaction and workload and for the site in general, as the ongoing updates are now much more frequent and contributions to them more direct and thereby inclusive. Accreditation of some kind may follow.

\section{Barbara and the ICT skills resources}

Our final case study features Barbara (a pseudonym), who is coordinator of ICT provision for one of the adult education services of the local authorities in the Greater Manchester area. Like Dee, she initially engaged with MOSI-ALONG because of her interest in spreading the DLC role throughout members of the local community; in her case, because of the mandate she held as a consequence of her formalised role. Also like Dee, she is responsible for a collection of web-based resources aimed at helping people improve their ICT skills, but these are held in Moodle, rather than on the "open" Web. Participants on ICT literacy courses organised by her service are given IDs and passwords through which they can access the information. Barbara also identified the barriers in the path of her DLC work as including lack of time and added mention of institutional constraints on what applications she was able to access and how she needed to conform to corporate communications strategies. For example, use of Facebook and Twitter was blocked from local authority-owned computers. Her senior management are not social media users and there was no awareness of the benefits of these media within the authority.

The early training sessions did raise awareness in Barbara of the DLC idea and the role that other institutions (including, but not limited to, the partners in MOSIALONG) could play in promoting it across the city. Barbara's confidence was increased, as was her knowledge of social media and other accessible technical solutions, such as Flip cameras, which could be used by community learners to document and disseminate their work. Her awareness of other initiatives, including Dee's, was also enhanced. However, no change could be seen or promoted in local authority policies. This restricted the use of social media or left the ICT literacy resources behind the walls of a virtual learning environment rather than out on the open web.

It is interesting to compare Barbara's situation with Dee's. Barbara has much less freedom to innovate or be flexible with her resources. Social media applications are blocked in her work place. Learners who want to use the site must register (it is in Moodle) and even making small changes to the appearance of the site require approval from a series of committees. 


\section{A. Whitworth et al.}

Therefore, Barbara's site shows evidence of Stages 3, 5 and 7 of the A/C process, but others have been skipped. It is arguable that even Stage 1, the initial identification of resources, has not really taken place, as the resources are largely generic in nature (e.g. materials produced for the European Computer Driving License, or ECDL) and have not emerged from a particular community or individual who was the original "owner" or developer of the resources. Hence, there is a detachment of the resources from the community and no intersubjective validation of their quality by the users. The resources are for the community - but not from them. The A/C model can help reveal this anomaly and show exactly where the disconnection has occurred, in ways that may be obscured by other, more instrumental and goal-oriented approaches to developing community content.

\section{Summary}

Summaries risk over-abstraction and our interpretation of what constitutes, for example, "limited" application of a particular stage can be disputed. Nevertheless, presenting a summary at this stage will help reveal how the $\mathrm{A} / \mathrm{C}$ model can highlight different aspects of digital inclusion within particular projects. The table below would also be useful if DLCs wanted to review these projects and identify where they might benefit from more support. The "100 Objects" project, for instance, has stalled at Stage 5; even a small boost from a DLC, who might spark the creation of digital images to illustrate the suggestions on the existing document, could push this through to the later stages.

\begin{tabular}{llllc}
\hline Stage & $\begin{array}{l}\text { Cabinets of } \\
\text { Curiosities }\end{array}$ & \multicolumn{1}{c}{ 100 Objects } & $\begin{array}{c}\text { Whalley } \\
\text { Range site }\end{array}$ & $\begin{array}{c}\text { ICT skills } \\
\text { resources }\end{array}$ \\
\hline $\begin{array}{l}\text { 1 - Identification } \\
\text { 2- Initial aggregation }\end{array}$ & Yes & $\begin{array}{l}\text { Yes } \\
\text { No, but validation } \\
\text { Shifted to Stage } 4\end{array}$ & $\begin{array}{l}\text { Yes } \\
\text { Yes }\end{array}$ & No \\
3-Digital creation & Yes & Yes & Yes & Yes \\
4- Digital aggregation & Yes & Yes & Yes & No \\
5- Sequencing and curation & Yes & Limited & Yes & Yes \\
6- Social media aggregation & Very limited & No & Under way & No \\
7- Accreditation & Limited & No & Under way & Yes \\
\hline
\end{tabular}

\section{Conclusion}

What have we learned about the A/C model? Firstly, Stage 2 is often very unconscious and often embedded in personal attributes such as confidence and skills. The urge to create digital content does not necessarily require an initial validation from friends, colleagues or other community members. This may support Giaccardi's observation (2012, p. 2: see above) regarding the way digital technologies have reduced barriers to participation in the creation of digital content. It is also conceivable that Stage 6 could be reached and successfully passed without the need for Stages 2 and 4. But if this happened, the complete digital content creation process would still have had validation with reference to each of the three domains: objective, intersubjective and subjective. This was the case for three of our four case studies. The fourth, Barbara's ICT resources, were only validated objectively; hence, their problems with 
relevance to the communities they were intended for and, ultimately, sustainability. The DLC role remained external to the community throughout.

Stage 5 is the one that seems hardest to push through. Of the three that have achieved a relevance to their immediate communities, Dee's site is the nearest case to achieving a wider reach and some form of accreditation, having been sequenced and curated by some kind of external authority (in this case, the City Council and local broadcasters) without losing its own identity nor relevance to the community from which it originates. But this process was very difficult to achieve with the "Cabinets of Curiosities" and has not begun with the "100 objects". Simon (2010) exhorts museums to become more participatory, but there are significant barriers in the way: professional identities, "locked-down" ICT infrastructures and concerns about validation all come into play. As Giaccardi says, new technologies may provide an environment in which digital inclusion can be more easily conceived, but simply having these tools - or the content - is not enough. As Garnett's original work (reported above, under "Origins") suggested, it is the learning processes which must change. Our evaluation of MOSI-ALONG suggests that the more significant learning processes must take place within formal and non-formal educational institutions, to open them up to community inputs, and not just see themselves as the dispensers of advice on content creation.

Case studies are, by their nature, selective. We have used four in this article as an initial test of the $\mathrm{A} / \mathrm{C}$ model, but more work is required before the validity of the framework can be assured. Nor were they the project's only interesting examples, by any means. Another community group developed links with the BBC during the project, acquiring from them some validation of the quality of their resources on sustainable city living.

What we do propose is that there is evidence that the $\mathrm{A} / \mathrm{C}$ model:

- forms a useful analytical tool for the study of community learning and CI, with a particular focus on producing collections of online content;

- that it could be used as the basis for developing training and development programmes for DLC;

- that it is a theoretical tool for understanding the nature of digital inclusion, with reference to theories of information behaviour and validation; and

- through a combination of all the above, can help in transforming the use of technologies in learning, and the learning process itself, in ways that promote digital inclusion (Seale 2010).

One hypothesis developed in this article is also in need of further testing: that being the suggestion that should any of the stages in the A/C model be missed, this will have a negative (and observable) influence on the quality of the resources, measured in terms of relevance; sustainability; accessibility; or usability. Barbara's resources, isolated behind institutional walls, show some evidence of this when compared to Dee's more open and dynamic collection, but this is only one case, and further investigation needs undertaking in order to provide more evidence to support this preliminary conclusion.

\section{Acknowledgements}

The project on which this research was based was funded by JISC (www.jisc.ac.uk) as part of the "Developing Community Collections" strand of the E-content 2011 programme. It involved a partnership between several organisations based in the city of Manchester, UK: The 


\section{A. Whitworth et al.}

School of Education at the University of Manchester; MOSI, the Museum of Science and Industry (www.mosi.org.uk); People's Voice Media (PVM), who help develop "citizen journalism" skills in communities (peoplesvoicemedia.co.uk); The Learning, Skills and Employment Network (LSEN) (www.lsen.org.uk); andMimas, a national data centre (www.mimas.ac.uk). Thanks are due to all these organisations for their help in conducting this research project.

\section{Note}

1. This section has previously appeared in Whitworth and Garnett (2012).

\section{References}

Barr, J. (2005) 'Dumbing down intellectual culture: Frank Furedi, lifelong learning and museums', Museums and Society, vol. 3, no. 2, pp. 98-114.

Blaug, R. (2007) 'Cognition in a hierarchy', Contemporary Political Theory, vol. 6, no. 1, pp. $24-44$.

Clarke, P. B. (1996) Deep Citizenship, Pluto Press, London.

Connell, J. P. \& Kubisch, A. C. (1998) 'Applying a theory of change approach to the evaluation of comprehensive community initiatives: progress, prospects and problems', in New Approaches to Evaluating Community Initiatives. Volume 2: Theory, Measurement and Analysis, eds K. Fulbright-Anderson, A. C. Kubisch \& J. P. Connell, The Aspen Institute, Queenstown, pp. 15-44.

Cook, J., et al., (2002) 'Informal eLearning Communities: the UK online perspective', 2002 International Conference on Computers in Education, Auckland, New Zealand, pp. 499-509.

Cummings, C., et al., (2006) Evaluation of the Full Service Extended Schools Initiative, Second Year: Thematic Papers, DfES publications, Nottingham.

Garnett, F. (2005) Community Development Model of Learning, Talk given to the Digitale Chancen Stiftung, Berlin, [online] Available at: http://www.digitale-chancen.de/transfer/ berlinerg/33.ppt

Garnett, F. \& Ecclesfield, N. (2008) 'Developing an organisational architecture of participation', British Journal of Educational Technology, vol. 39, no. 3, pp. 468-474.

Garnett, F. \& Ecclesfield, N. (2009) Proposed model of the relationships between Informal, nonformal and formal learning, Paper presented at IADIS-CELDA, Rome, [online] Available at: http://www.iadisportal.org/digital-library/proposed-model-of-the-relationships-betweeninformal-non-formal-and-formal-learning

Giaccardi, E. (2012) Heritage and Social Media: Understanding Heritage in a Participatory Culture, Routledge, London.

Gurstein, M. (2007) What Is Community Informatics: And Why Does It Matter? Polimetrica, Milan.

Habermas, J. (1974) Theory and Practice, Heinemann, London.

Habermas, J. (1987) The Theory of Communicative Action Volume 2: Lifeworld and System - A Critique of Functionalist Reason, Polity, Cambridge.

Jonassen, D., et al., (2003) Learning to Solve Problems with Technology: A Constructivist Perspective, Merrill, London.

Keen, A. (2007) The Cult of the Amateur: How Today's Internet Is Killing Our Culture and Assaulting Our Economy, Nicholas Brearley, London.

Kemmis, S. (2001) 'Exploring the relevance of critical theory for action research: emancipatory action research in the footsteps of Jürgen Habermas', in Handbook of Action Research: Participative Inquiry and Practice, eds P. Reason \& H. Bradbury, Sage, London, pp. 91-102.

Luckin, R. (2010) Redesigning Learning Contexts: Technology-Rich, Learner-Centred Ecologies, Routledge, London.

Rosson, M. B. \& Carroll, J. M. (2009) 'Developmental learning communities', Journal of Community Informatics, vol. 1, no. 2, pp. 148-151.

Seale, J. (2010) Digital Inclusion: A Research Briefing by the Technology-Enhanced Learning Phase of the Teaching and Learning Research Programme, London Knowledge Lab, London, [online] Available at: http://www.tlrp.org/docs/DigitalInclusion.pdf

Shenk, D. (1997) Data Smog: Surviving the Information Glut, Harper Collins, New York. 
Simon, N. (2010) The Participatory Museum, [online] Available at: www.participatorymuseum. org

Smith, M. \& Cook, J. (2002) Progress Report on Study of UK Online Centres. Submitted to British Educational and Communications Technology Association (Becta). Learning Technology Research Institute, University of North London, March 2002.

Thompson, D. (2008) Counterknowledge, Atlantic, London.

Wenger, E. (1998) Communities of Practice: Learning, Meaning and Identity, Cambridge University Press, Cambridge.

Wenger, E. (2000) 'Communities of practice and social learning systems', Organization, vol. 7, no. 2, pp. 225-246.

Wenger, E., White, N. \& Smith, J. D. (2009) Digital Habitats: Stewarding Technology for Communities, CPSquare, Portland, OR.

Whitworth, A. (2009) Information Obesity, Chandos, Oxford.

Whitworth, A. (in press) A Critical Theory of Information Literacy: A Tripartite Approach, Chandos, Oxford.

Whitworth, A. \& Garnett, F. (2012) 'Aggregate-then-Curate: digital learning champions and informational resources', in Proceedings of the 8th International Conference on Networked Learning 2012, eds. V. Hodgson, C. Jones, M. de Laat, D. McConnell, T. Ryberg \& P. Sloep, Maastricht. 